\title{
Smart Farming Based on IoT: Nepal Perspective
}

\author{
Anup Acharya \\ School of Engineering, Pokhara University, Nepal \\ anpchry[at]yahoo.com
}

\begin{abstract}
This paper is about how Internet of Things (IoT) plays a vital role in farming. IoT based farming is the smart farming system so that if we apply this technology with traditional farming then it would definitely be emerging because of its ability for providing information about the farming field. The main aim of this paper is making use of latest technology like Internet of Things in agriculture for smart farmingwith the help of different sensors like temperature, humidity, and pressure through wireless network system. These sensors are used for monitoring environment and farmingareaas well as for sending the exact data to farmerthrough server and android system.
\end{abstract}

Keywords: Farming, Agriculture, Internet of Things(IoT), Cloud Based System, etc

\section{Introduction}

\subsection{Background}

Agriculture is the basic source of live hood of people in Nepal. $68 \%$ of total economy and most of Nepalese people are dependent upon farming Central Bureau of Statistics Nepal., [1]. There is not much crop development in farming in past decade, because there was not enough technology so food prices are continuously growing up daily because only less farming product are developed and crop rate is declined. By using different technology in farming, we can push toward production of farming product so that we can only fulfill the market demand. These technology tools are Internet of Things, Cloud based system, and wireless system these devices are widely used in connecting devices and collection of information. The main communication media is Raspberry Pi Model 3B in build Wi-Fi module and the information is stored in memory card or computer storage devices. There is used in powerful processer system so it sends real time data to our android devices and farmer can easily operate the system. But farmers are still using traditional methods for farming system, which gives the result in low product development. So, there is less amount of farming product is in market. Combination of traditional method with techno tools definitely can improve the production through automation. By using Internet of Thing, we can expect the increase in production with low cost by monitoring the efficiency of the soil, moister, temperature and humidity monitoring, field pressure monitoring and water tank indication minimize the energy waste Tanmay Baranwal et al., [2]. Inbuilt Wi-Fi system of Raspberry Pi Model 3B processor collect the data fromdifferent/different sensors and send it to main server after that we can observe and apply it from our android devices Nelson Sales et al., [3]. The combination of traditional methods with latest technologies like Internet of thing and wireless network only can lead to farming modernization.

\subsection{Problem Statement}

Although Nepal is agro-based country but due to low production, it depends on import crops. In this regard it is necessary to increase crops production for which this smart farming concept may become milestone.

\subsection{Objective}

This paper is focused on use of IoT based smart farming in the field of agriculture in order to increase the crop production.

\section{Literature Review}

Nikesh Gondchawar et al., [5] work on how IoT based smart farming system makes agro life simple. The main aim of this paper making farming system smart using Internet of Thing, Cloud based system and android system. First different sensors track the field data then it sends the data to server system via wireless network and finally users can easily monitor and visualize these data through his/her android devices. It monitors temperature, humidity using different sensors modules.

Rajalakshmi P.et.al., [6] work on IoT based smart farming system. This paper described to monitor the farming field using different sensors system like moisture sensors, temperature sensors, humidity sensors, light sensors and automated water level indication system. The raspberry Pi model 3 capture the real time data of field through different sensors and sent to web server using wireless transmission and JSON format is used for data encoding to maintain server database Li Minbo et al., [7]. The notifications are sent to farmers mobile periodically and farmers can be able to monitor the field conditions from anywhere.

\section{Experimental Method}

Volume 11 Issue 2, February 2022 www.ijsr.net 


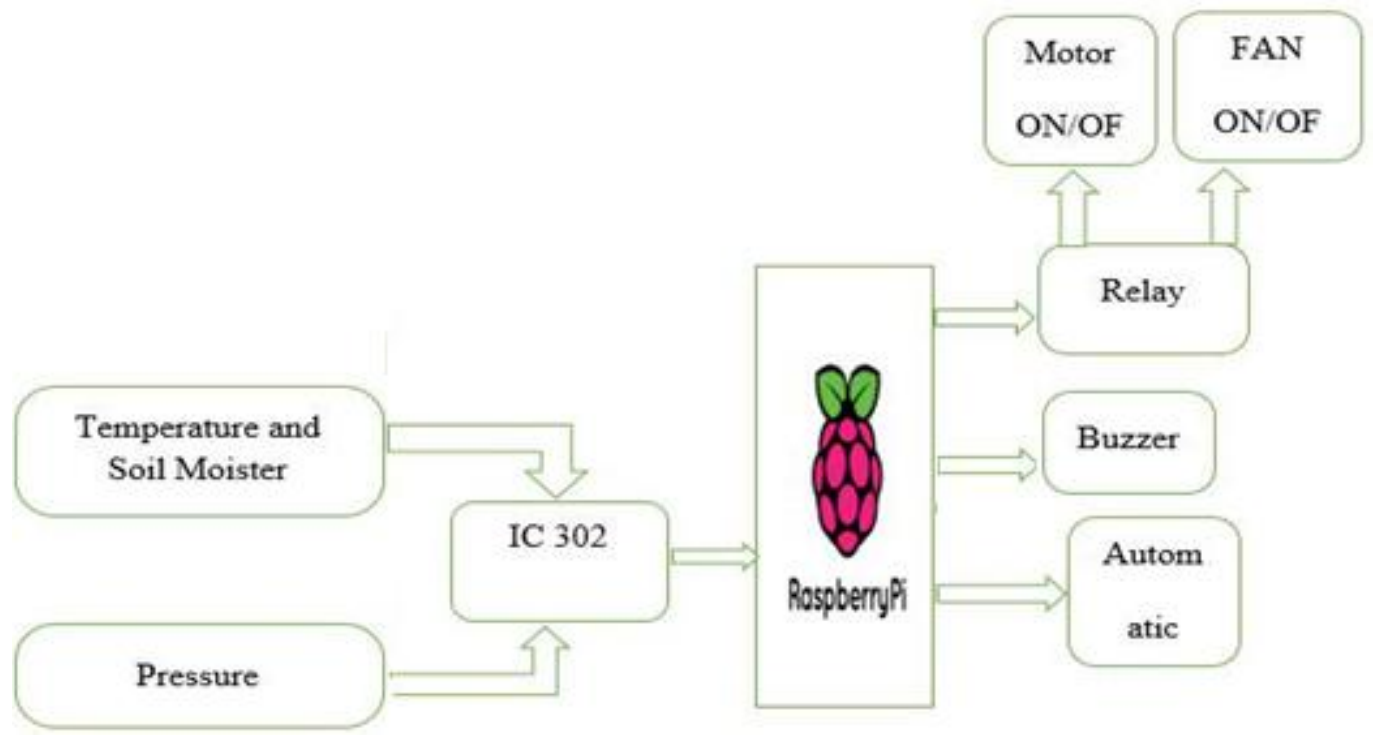

Figure 1: System Block Diagram

The diagram is about the overall system diagram of IoT based smart farming system. This system is divided into two parts one is transmitter session which has mobile application with a smart phone system and next one is receiver session and there has over all system. In receiver session we used raspberry pi model $3 \mathrm{~B}$ for receiving the data from Mob application system and it also transmitted the real time data to transmitter. The real time data are temperature reading, humidity reading, pressure reading and moisture status. Then User run the system on the basis ofdata. If there is temperature is above 35 degrees then user automatically turn on the Fan and if the temperature is less than 28 then user turn off the Fan from his/her mobile devices. Similarly, if there is need water for system then user automatically turn ON water from mobile? Similarly other system run.

Here we use two processor device one is raspberry pi for communicating device which take the data from sender/ User and give data to user. Similarly, there is used Arduino UNO for properly operate the system. We connected Humidity sensor, pressure sensor, temperature sensor and water level indicator in this processor. It operates through the Raspberry Pi. First User send the instruction from his/her mobile device after that Raspberry Pi receive that instruction and send it to Arduino then only system operate properly.

The data has store in cloud database. The system is completely automated and state of condition of the system can be known by the mobile phone, raspberry Pi through IP address. From these information's the farmers identify and change the condition, in the raspberry, process using python code it generates the IP address all the sensor data is available in that address and also motor condition will also contains, at any place these IP address search in google by using Raspberry Pi, mobile and system the data will display on our devices. This can be summarizing as:

Volume 11 Issue 2, February 2022

www.ijsr.net

Licensed Under Creative Commons Attribution CC BY 


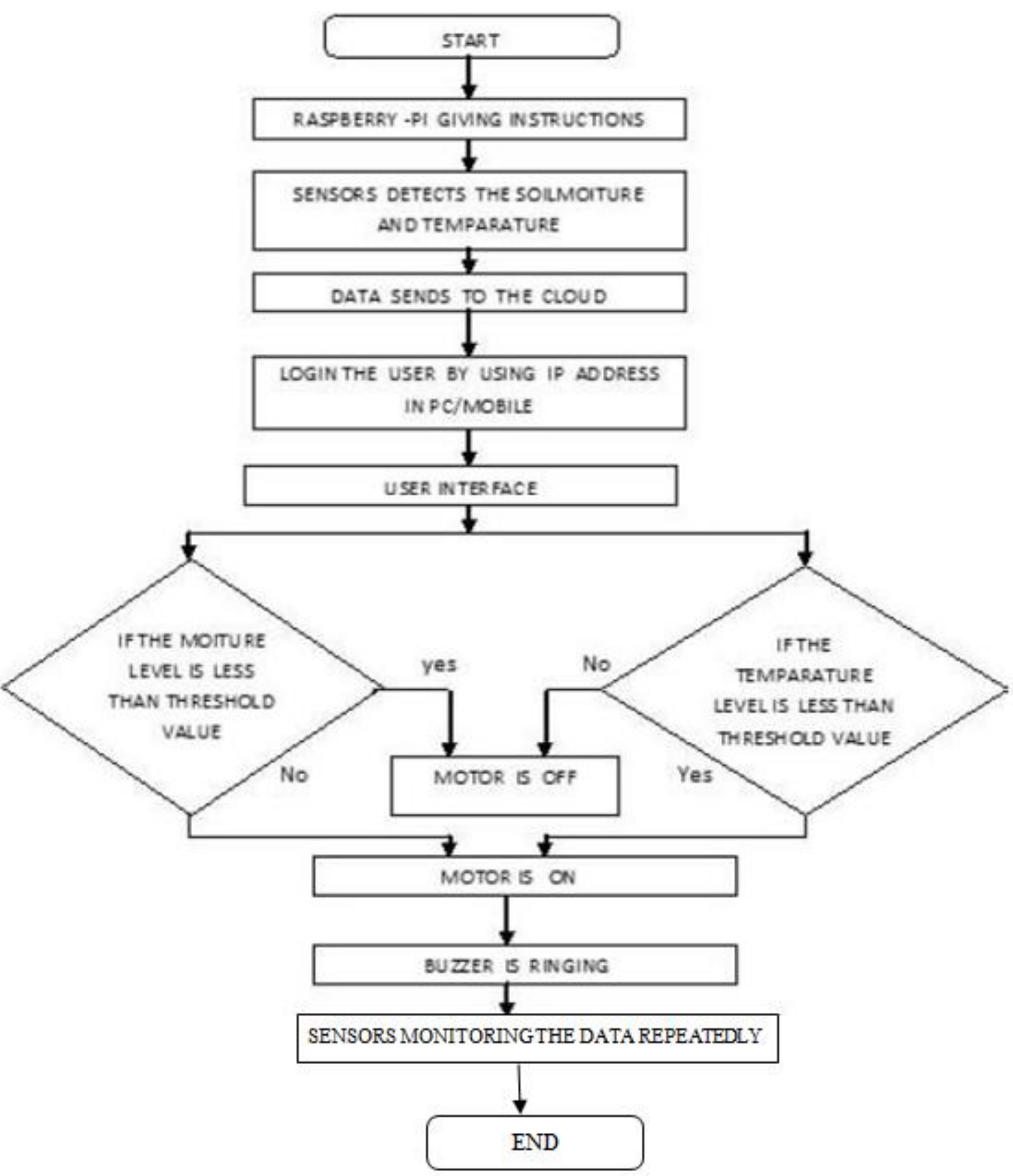

Figure 2: Flow chart of the IOT based smart farming System

\section{Results and Discussions}

The data obtain from sensors are stored in the cloud and can be monitored by farmer through his mobile/ PC. The real time results and the status of the system has taken on $3 \mathrm{G} / 4 \mathrm{G}$ mobile system is as shown in the Fig (3). The values which actually occur from the system are observed by farmer; with his intervention at his crop fields the irrigation ran automatically. Raspberry $\mathrm{Pi}$ model $3 \mathrm{~B}$ processed and correlated huge data obtained from the sensors checks at every time to the threshold values. Here calibration of the sensors system is so important. The system displays temperature value and condition of soil moisture, based on the two sensors the condition of motor. The status of the system can able to check at remote place and complexity of the system is less so we can do trouble shooting easily in firmware.

Volume 11 Issue 2, February 2022 www.ijsr.net 


\section{International Journal of Science and Research (IJSR)}

ISSN: 2319-7064

SJIF (2020): 7.803

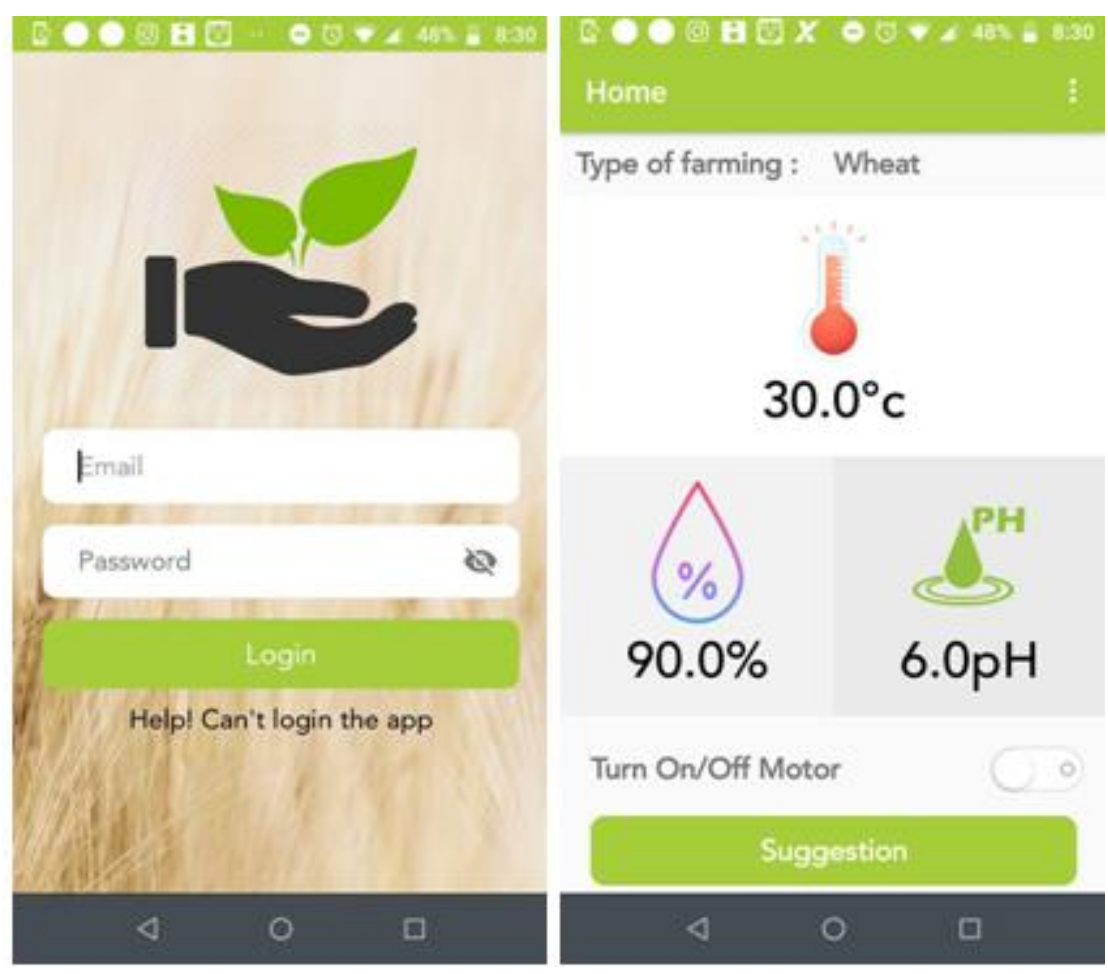

Figure 3: Mobile Application

\section{Conclusion}

A smart farming system is portable,cost effectiveand user friendly. All observations and experimental tests prove that IoT Based system is a complete solution to field activities and irrigation problems. With the help of this approach the irrigation system is completely automated.It also provides real-time information about the lands and crops that will help farmers to make right decisions. So, the implementation of such a system in the field of agriculture can definitely help to improve the overall production.

\section{References}

[1] Central Bureau of statistics Nepal, STATISTICAL YEAR BOOK OF NEPAL-2017.

[2] Tanmay Baranwal, Nitika , PushpendraKumarPateriya "Development of IoT based Smart Security and Monitoring Devices for Farming" $6^{\text {th }}$ International Conference - Cloud System and Big Data Engineering, 978-1-4673-8203-8/16, 2016 IEEE.

[3] Nelson Sales, Artur Arsenio, "Wireless Sensor and Actuator System for Smart Irrigation on the Cloud" 9781-5090-0366-2/15, 2nd World forum on Internet ofThings (WF-IoT) Dec 2015, published in IEEE Xplore jan 2016.

[4] Nikesh Gondchawar, Prof. Dr. R. S. Kawitkar, "IoT based Smart Farming" International Journal of Advanced Paper in Computer and Communication Engineering Vol. 5, Issue 6, ISSN (Online) 2278-1021 ISSN (Print) 2319 5940, June 2016.

[5] Rajalakshmi.P, Mrs.S.DeviMahalakshmi"IOT Based Crop-Field Monitoring and Irrigation Automation" 10th International conference on Intelligent systems and control (ISCO), 7-8 Jan 2016 published in IEEE Xplore Nov 2016.
[6] Yongxian Song, Juanli Ma, Xianjin Zhang, Yuan Feng, "Design of Wireless Sensor Network-Based Greenhouse Environment monitoring and Automatic Control System", JOURNAL OF NETWORKS, VOL. 7, NO. 5, MAY 2012.

[7] Li Minbo, Zhu Zhu, Chen Guangyu, "Information Service System of Farming IoT", AUTOMATICA 54(2013) 4, 415-426.

[8] Mohamed RawideanMohdKassim, Ibrahim Mat, Ahmad Nizar Harun "Wireless Sensor Network in Precision Farming Application" 978-1-4799-4383- 8/14,

Volume 11 Issue 2, February 2022

www.ijsr.net

Licensed Under Creative Commons Attribution CC BY 